\title{
EQUIVALENCE OF SOME MATRIX INEQUALITIES
}

\section{Gantong He}

Abstract. In the present article, some Kantorovich type and Wielandt type matrix inequalities and their equivalent forms are discussed respectively, and the equivalence of these Kantorovich type inequalities with the corresponding Wielandt type inequalities are established too.

Mathematics subject classification (2010): 15A42 15A45.

Keywords and phrases: Wielandt inequality, Kantorovich inequality, Cauchy-Schwarz inequality, singular value decomposition.

\section{REFERENCES}

[1] J. K. Baksalary And S. Puntanen, Generalized matrix versions of the Cauchy-Schwarz and Kantorovich inequalities, Aequationes Math. 41 (1991), 103-110.

[2] S. W. Drury, Shuangzhe Liu, Chang-Yu Lu, S. Puntanen and G. P. H. Styan, Some comments on several matrix inequalities with applications to canonical correlations: historical background and recent developments, Sankhyā: The Indian Journal of Statistics, San Antonio Conference: selected articles 64, Series A, Pt. 2 (2002), 453-507.

[3] Shuangzhe Liu And Heinz Neudecker, Several matrix Kantorovich-type inequalities, J. Math. Anal. Appl. 197 (1996), 23-26.

[4] A. W. Marshall And I. Olkin, Matrix versions of the Cauchy and Kantorovich inequalities, Aequationes Math. 40 (1990), 89-93.

[5] B. Mond And J. E. PeČArić, A matrix version of the Ky Fan generalization of the Kantorovich inequality, Linear and Multilinear Algebra 36 (1994), 217-221.

[6] B. Mond AND J. E. PeČARIĆ, Matrix versions of some means inequalities, Austral. Math. Soc. Gaz. 20 (1993), 117-221.

[7] J. E. PeČarić, S. Puntanen, And G. P. H. Styan, Some further matrix extensions of the Cauchy-Schwarz and Kantorovich inequalities, with some statistical applications, Linear Algebra Appl. 237/238 (1996), 455-476.

[8] Song-Gui Wang And WaI-Cheung IP, A matrix version of the Wielandt inequality and its applications to statistics, Linear Algebra Appl. 296 (1999), 171-181.

[9] Fu-Zhen ZhANG, Equivalence of the Wielandt inequality and the Kantorovich inequality, Linear and Multilinear Algebra 48 (2001), 275-279.

[10] R. A. Horn And C. R. Johnson, Matrix Analysis, Cambridge University Press, New York, 1985.

[11] Fu-Zhen Zhang, Matrix Theory: Basic Results and Techniques, Springer-Verlag, New York, 1999. 